九州大学学術情報リポジトリ

Kyushu University Institutional Repository

Taxonomic Studies on the Genus Telenomus Haliday of Japan and Korea (Hymenoptera, Scelionidae) Part I

Ryu, Joon

Entomological Laboratory, Faculty of Agriculture, Kyushu University

Hirashima, Yoshihiro

Entomological Laboratory, Faculty of Agriculture, Kyushu University

https://doi.org/10.5109/23810

出版情報: 九州大学大学院農学研究院紀要. 30 (1)，pp.9-30，1985-09. Kyushu University バージョン：

権利関係 : 


\title{
Taxonomic Studies on the Genus Telenomus Haliday of Japan and Korea (Hymenoptera, Scelionidae) * Part I
}

\author{
Joon Ryu** and Yoshihiro Hirashima \\ Entomological Laboratory, Faculty of Agriculture, \\ Kyushu University, Fukuoka 812, Japan
}

(Received May 17, 1985)

\begin{abstract}
The geus Telenomus Haliday of Japan and Korea is revised. Twenty-five species are recognized, including 5 new species ( 3 from Japan and 2 from Korea). These are divided into 2 groups according to the female antennal segments.

In Part I, 15 species belong to the group A are treated. Telenomus koreanus Ryu, sp. n. is described from Korea, and T. sphaeroceps Ryu, sp. n. and T. yamagishii Ryu, sp. n. are described from Japan. Five species, i. e., T. nawai Ashmead, cirphivorus Liu, gifuensis Ashmead, benefactor Crawford and strelzovi Vassiliev are recorded from Korea and 4 species, i. e., T. cirphivorus Liu, lucullus Nixon, benefactor Crawford and wullschlegeli Mayr are recorded from Japan for the first time, respectively.
\end{abstract}

Parasitic wasps of the genus Telenomus Haliday of Japan and Korea are revised and 25 species are recognized from this part of the world. Telenomus is a large genus and cosmopolitan in distribution. Prior to our study, 12 species of Telenomus have been known from Japan and 2 species (common to Japan) from Korea. In this paper, 5 species ( 3 from Japan and 2 from Korea) are described as new; 6 species are recorded from Japan for the first time and 7 species (5 common to Japan) are also recorded from Korea for the first time.

Telenomus is an important but difficult genus. Preferential treatment has been given to the female sex only because the males of Telenomus tend to be so much alike in external appearance that is almost difficult to construct a workable key for them. We have adopted the terminology used by Masner (1930). In describing the species, however, the head was measured according to its greatest width and its median length; the latter is defined as the distance between a line at right angle to the frons and another joining the median posterior margin of the head as seen from above.

We are much indebted to Dr L. Masner of Agriculture Canada for his identification of Japanese specimens of the Scelionidae at the generic level.

* Contribution from the Entomological Laboratory, Faculty of Agriculture, Kyushu University, Fukuoka (Ser. 3, No. 173).

** Present address: Korea Atomic Energy Research Institute, P. 0. Box 7, Cheong Ryang, Seoul, Korea. 
We are also grateful to Prof. T. Tachikawa of Ehime University, Prof. T. Okadome of Meijo University and Mr. K. Yamagishi of Kyushu University (now Meijo University) for their kind help in many ways, especially the specimens. One of the authors, Ryu, wishes to thank Associate Professor K. Morimoto, Dr. T. Tadauchi and Miss C. Okuma for their kind advice given in the course of his study at Kyushu University.

\section{Genus Telenomus Haliday, 1833}

Telenomus Haliday, 1833, Ent. Mag., 1: 271.

Type-species : Telenomus brachialis Haliday, 1833

The genus Telenomus Haliday is well known and world wide in distribution; the species belonging to this genus are numerous and usually parasitize the eggs of Lepidoptera, and rarely those of bugs belonging to the Pentatomidae and Miridae, or those of the Chrysopidae and Tabanidae. Up to the present, so far as we know, about 520 species have been described under this genus in the world,

This genus may be characterized as follows:

Head large, transverse, broader than thorax. Occiput concave, not margined. Frons smooth and glabrous in greater part. Eyes hairy and large. Ocelli triangulary arranged and widely separated, posterior ocelli very close to inner orbits. Antennae inserted close to clypeus, in female usually 11 -segmented, rarely lo-segmented; apical segment conical in both sexes.

Thorax ovoid; mesoscutum finely sculptured, without notauli ; scutellum smooth or feebly sculptured laterally. Fore wings pubescent, ciliated ; stigma1 vein rather long, usually longer than marginal vein; postmarginal vein long. Hind wings usually narrow with rather long fringes. Legs moderate, femora subclavate, tibia1 spurs weak, tarsi 5-segmented, not so long as tibiae.

Metasoma elongated, distinctly longer than broad; first tergum broader than long; second tergum always the broadest and longest, although often broader than long, striated at base, with striae very short and never beyond the middle of tergum; the following terga all short.

This genus may be divided into two groups according to the number of antenna1 segments of the female, i. e., the Group A (11-segmented) and the Group B (lo-segmented).

Group A: This group includes 19 species, i. e., Telenomus promachivorus, T. nawai, T. koreanus, T. hakonensis, T. cirphivorus, T. lucullus, T. gifuensis, T. nakagawai, T. benefactor, T. wullschlegeli, T. sphaeroceps, T. yamagishii, T. poeta, T. strelzovi, T. dendrolimi, T. rowani, $\mathbf{T}$. acrobates, $\mathbf{T}$. dignus and Tel enomus sp. 1.

Group B: This group includes -5 species, i. e., Telenomus sudoensis, T. monodactylus, T. euproctidis, T. kuboi and T.kyushuensis.

Telenomus atamiensis can not be placed in any of them because it is known by the male only.

In the first part of this paper (Part I), the first 15 species of the Group A are dealt with. 


\section{( I ) Group A: Antennae of female 11-segmented}

(1) Telenomus promachivorus (Gahan, 1924)

(Figs. 8, 28, 47)

Phanurus promachivorus Gahan, 1924, Proc. U.S. Nat. Mus., 65, art., 4: 21. Female and male.

Teknomus promachivorus: Masner et Musebeck, 1968, U.S. Nat. Mus. Bull., 270: 69.

Telenomus promachivorus:Kozlov, 1971, Trudȳ vses. ent. Obshch., 54: 3-67.

The head of this species is similar to benefactor, but differs from it in having a prominent protuberance on the dorsum of the first metasomal tergum. This species is further separable from benefactor in having the metasoma pointed and elongate apically and the first funicle segment a little shorter than pedicel. The male differs from the female by the absence of the protuberance on the metasoma.

This species was originally described from Japan (Koiwai) by Gahan(1924) from eight females and seven males bred from the eggs of Promachus yesonicus Bigot which was taken by Clausen.

Female: Black. Antennae entirely dark brown. Legs brownish testaceous; trochanters and basal segments of tarsi yellowish brown.

Head transverse as seen from above, about 2.3 times as broad as its median length and nearly as broad as thorax. Vertex roundly convex behind posterior ocelli, finely reticulate-sculptured with sparse, short hairs; occiput broadly concave, smooth and shining; preoccipital carina situated below the top of vertex. Frons in greater part smooth and shining but minutely punc. tate-sculptured near eye. Eyes covered with extremely short hairs, 1.5 times as long as broad; interocular distance to the width of head, as 7: 16, as seen in front. Posterior ocellar distance 1.6 times as long as lateral ocellar distance. Antennae ll-segmented; radicle about quarter as long as scape; scape 4.7 times as long as broad, a little shorter than following four segments combined; pedicel 2.2 times as long as broad, 1.3 times as long as first funicle segment; first more slender than pedicel, about twice as long as broad and 1.3 times as long as second; second 1.5 times as long as broad, 1.2 times as long as fourth ; fourth as long as broad; club 5-segmented, proximal first and second segments a little broader than long, third and fourth subquadrate and apical segment conical-ovate.

Thorax slightly broader than metasoma ; mesoscutum closely reticulatesculptured, covered with short hairs; scutellum distinctly transverse with some sparse punctures; propodeum broadly and deeply excavated for reception of protuberance on first metasomal tergum, only lateral angles visible from above. Fore wings about 3.1 times as long as broad; postmarginalis indistinct, but approximately 2.7 times as long as stigmalis and submarginalis 1.3 times as long as postmarginalis. Hind wings 5.5 times as long as broad; fringes about $3 / 5$ of the greatest width of hind wing.

Metasoma pointed-elongate apically, narrower than thorax (7:8) and 4.4 times as long as broad; first tergum transverse with a prominent round protuberance dorsally; second tergum slightly longer than broad with longitudinal striae; following terga gradually tepering toward apex; ovipositor project- 
ing, about $1 / 2$ of the metasoma.

Male: Black. Antennae dark brown except for scape which is testaceous. Legs yellowish brown except for coxae, hind femora and apices of tarsi which are dark brown.

Antennae 12-segmented; radicle quarter as long as scape ; scape 4.8 times as long as broad, almost equal to following three segments combined; pedicel nearly twice as long as broad, as long as first flagellar segment; first 1.5 times as long as broad, 0.8 times as long as second ; second 2.3 times as long as broad, 1.3 times as long as third; third nearly as long as first; fourth to ninth subquadrate ; apical segment conical, 1.6 times as long as broad. Thorax as broad as and about as long as metasoma. Metasoma ovate; first tergum transverse, without a protuberance above, striate basally ; second tergum about half as long as metasoma; following terga strongly transverse. Otherwise like female, but smaller.

Length: Male $0.9 \mathrm{~mm}$, female 1.2-1. $6 \mathrm{~mm}$.

Host : Promachus yesonicus Bigot.

Distribution: Japan (Kyushu, Shikoku, Honshu), USSR.

Specimens examined: 7 females, Kamiozoegawa, Fuji, Saga Pref., Kyushu, 10. viii. 1973 (K. Yamagishi) ; 1 female, Kamiozoegawa, Fuji, Saga Pref., Kyushu, 6. ix. 1973 (K. Yamagishi) ;1 female, Kamiozoegawa, Fuji, Saga Pref., Kyushu, 25. ix. 1973 (K. Yamagishi) ; 1 male, 2 females, Matsuyama, Shikoku, 31. vii. 1974 (K. Ito), bred from eggs of Promachus yesonicus.

\section{( 2) Telenomus nawai Ashmead}

Telenomus nawai Ashmead, 1904, J. New York Ent. Soc., 12 (2): 72 . Female and male.

Telenomus nawai: Masner and Muesebeck, 1968, U.S. Nat. Mus. Bull., 270: 67.

Telenomus nawai: Hirashima and Yamagishi. 1981, J. Fac. Agr., Kyushu Univ., 25 (4) :156-

158. Redescription.

This species is similar to acrobates, but differs from the latter in having the eyes bare and the upper portion of eye very narrow, somewhat angulate behind.

This species was described from 18 specimens (both sexes) bred by Mr. N. Nawa from the eggs of an unknown Lepidopteron. Type No. 7123, USNM.

For the description of this species, see Hirashima and Yamagishi (1981).

Length: Female and male, about $0.57 \mathrm{~mm}$.

Host: Unknown.

Distribution: Japan (Honshu), Korea. This is the first record of this species from Korea.

Specimens examined: 1 female, Kwangneung, Kyunggi-do, Korea, 9. ix. 1982 (J. Ryu).

\section{(3) Telenomus koreanus Ryu, sp. $n$.}

(Figs. 9, 27, 54)

This species is similar to gifuensis, but is larger, and the interocular distance is distinctly shorter than in the latter. This species is further distinct in having the head with postero-lateral portions just behind eyes angulate, 
the vertex well convex, the occiput concave as seen from above, the antenna1 club distinctly 6-segmented, the first funicle segment distinctly longer than pedicel and the fore coxae black.

Female: Black. Antennae dark brown except for radicle and scape which are yellowish brown. Legs reddish yellow or more yellowish, with fore coxae blackish. Wings tinged with yellowish brown, veins brown.

Head transverse as seen from above, 2.1 times as broad as its median length and slightly broader than thorax $(11: 10)$. Vertex well convex, distinctly reticulate-sculptured throughout, covered with sparse, very short hairs. Occiput concave as seen from above and sculptured as in vertex. Preoccipital carina abruptly angled and only present behind eyes. Frons well convex, very broad, in greater part smooth and shining; subocular space broadly microscopically punctate-sculptured near eye ; temple sculptured as in subocular space. Eyes large with sparse, very short hairs, 1.4 times as long as broad; interocular distance markedly shorter than width of head as seen in front (9: 23). Posterior ocellar distance 1.5 times as long as lateral ocellar distance. Antennae 11-segmented; radicle 2.1 times as long as broad, about 1/5 as long as scape; scape 5.3 times as long as broad, 3.2 times as long as pedicel; pedicel 2.2 times as long as broad, shorter than first funicle segment (8 : 11 ) ; first markedly longer than other funicle segments, 2.9 times as long as broad and 1.3 times as long as second ; second 2.3 times as long as broad, 1.5 times as long as third; third 1.5 times as long as broad, a little longer than fourth; fourth as long as broad; club 6-segmented, proximal first segment a little narrower than next segments, second to fourth transverse and apical segment conical-ovate.

Thorax slightly longer than broad (5:4), as long as metasoma; mesoscuturn densely hairy, well convex with distinct reticulate-sculpture throughout; scutellum rather large, semicircular, in greater part smooth and shining with sparse punctures and rather long hairs; metanotum and propodeum strongly sculptured. Fore wings rather broad, 2.7 times as long as broad; stigmalis rather long, about 2.3 times as long as postmarginalis and submarginalis 1.4 times as long as postmarginalis. Hind wings about 5 times as long as broad ; fringes about $1 / 3$ of the greatest width of hind wing.

Metasoma about 1.5 times as long as broad, slightly longer than thorax $(9: 8)$; first tergum strongly costate all over with sparse, long hairs laterally; second tergum a little longer than broad, longitudinally striated basally, elsewhere smooth and shining; following terga strongly transverse, feebly punctulate throughout with sparse hairs. Ovipositor slightly projecting the tip of metasoma.

Length: $1.2 \mathrm{~mm}$.

Male and host: Unknown.

Distribution: Korea.

Type material: Holotype: female (Type No. 2215, Kyushu Univ.), Mt. Sudo (700 m), Kyungsangpuk-do, Korea, 29. v. 1970 (K. Yamagishi). Paratype :1 female, Mt. Sudo (700 m), Kyungsangpuk-do, Korea, 27. v. 1970 (K. Yamagishi); 1 female, Mt. Sudo (700 m), Kyungsangpuk-do, Korea, 17-18, vii. 1971 (K. Ya- 
magishi) ; 1 female, Mt. Chenonmasan, Kyunggi-do, Korea, 3. x. 1982 (J. Ryu).

\section{( 4 ) Telenomus hakonensis Ashmead}

Telenomus hakonensis Ashmead, 1904, J. New York Ent. Soc.,12 (2) : 73. Female.

Telenomus hakonensis: Masner and Muesebeck, 1968, U.S. Nat. Mus. Bull., 270: 65.

Telenomus hakonensis: Hirashima and Yamagishi, 1981, J. Fac. Agr., Kyushu Univ., 25 (4) : $155-156$.

This species is similar to gifuensis, but differs from it in having the first funicle segment distinctly elongate, much longer than pedicel and the metasoma broadest beyond the middle as seen from above. This is further characterized by the upper portion of head including vertex distinctly reticulate, the posterior margin of head distinctly angulate or nearly carinate behind eye and rather rounded in the middle.

This species was described from 2 female specimens taken from Japan (Hakone) by A. Koebele. Type No. 7125, USNM. The lectotype was designated by Masner and Muesebeck in 1968. According to them, the cotype female is missing.

For the redescription of this species, see Hirashima and Yamagishi (1981).

Length : $1.4 \mathrm{~mm}$.

Male and host: Unknown.

Distribution: Japan (Honshu, Hokkaido). mati).

Specimen examined: 1 female, Sounkyo, Hokkaido, 9. vii. 1965 (K. Kushige-

\section{(5) Telenomus cirphivorus Liu}

(Figs. 24, 44)

Telenomus cirphivorus Liu, 1959, Acta Soc. ent. Csl., 56: 158. Female and male.

This species is redescribed based on ten males taken in Japan and Korea. The male of this species is easily recognizable by the head and prono. turn reddish yellow, and the mesoscutum distinctly flattened. Three females taken in these areas which are thought to be the female of this species differ slightly from the male in having the mesoscutum convex and the head and pronotum black.

The female of this species is similar to acrobates, but differs from the latter in having the interocellar space distinctly poculiform, head distinctly transverse, antennae chestnut brown and legs paler.

Male: Coloration of male is variable, especially in head and thorax. The male of this species may be separable into two forms, i. e., yellow form and black form, by the color of body.

Yellow form: Frons and entire region below mid ocellus and pronotum reddish yellow; vertex and mesopleuron somewhat more darker than those on frons; eyes along the edge somewhat yellowish, but central part more darkened. Antennae deep brown except for scape which is yellowish brown. Fore and middle legs yellowish with apical tarsal seguments fusco-testaceous. Hind leg similarly colored, except for femora and tibiae which are somewhat fuscous. 
Black form: Body entirely black, but the head and thorax somewhat blackish brown. Legs and antennae as in the yellow form.

Head distinctly transverse, about 3 times as broad as its median length as seen from above and a little broader than thorax (15:14); head with frontal region well convex. Vertex rather broad, flat, smooth, shining; microscopically finely reticulate on ocellocular space and posterior portion of vertex only with sparse, very short hairs; hind margin not sharply carinate, rounded into occiput. Frons slightly convex, broad, smooth and shining; subocular space broadly microscopically punctate-sculptured near eye. Eye rather small, covered with dense short hairs and 1.3 times as long as broad; interocular distance to width of head as seen in front, as $8: 15$. Interocellar space distinctly poculiform, i. e., mid ocellus situated nearly on posterior ocellar line; posterior ocellar distance 1.6 times as long as lateral ocellar distance. Antennae 1\&segmented; radicle a little shorter than $1 / 3$ of scape, 2.4 times as long as broad; scape 4.3 times as long as broad, about 3.2 times as long as pedicel; pedicel 1.5 times as long as borad, a little longer than first flagellar segment; first to third equal in length, about 1.5 times as long as broad and 'longer than following segments ; fourth to sixth almost equal in length and width, slightly longer than broad; seventh 1.5 times as long as broad, as long as eighth; eighth 1.2 times as long as broad; ninth 1.4 times as long as broad, a little shorter than eighth; apical segment conically elongate, 2.7 times as long as broad.

Thorax nearly as long as broad; mesoscutum distinctly flat with even and close punctate-sculptures and covered with short, pale hairs; scutellum semicircular, smooth but microscopically, sculptured, covered with hairs which are a little longer and sparser than those on mesoscutum; metanotum transverse, strongly sculptured. Fore wings rather broad, hyaline, ciliated and about 2.7 times as long as broad; stigmalis about 0.4 times as long as postmarginalis; submarginalis about 1.6 times as long as postmarginalis. Hind wings broadened beyond nervature, about 6 times as long as broad; fringes about 3/5 of the greatest width of hind wing.

Metasoma a little longer than thorax, about 1.3 times as long as broad; first tergum transverse with longitudinal costae all over; second tergum nearly as long as broad, smooth and shining with extremely short striae at base; following terga distinctly transverse,. smooth and shining with coarse, short hairs.

Female: Black. Antennae chestnut brown except for radicle and base of scape paler. Legs fuscous except for trochanter, bases of femora and tarsi which are pale yellow. Vertex more abruptly angled behind eye than in male; frons smooth and shining. Mesoscutum more convex than in male. Antennae U-segmented; scape 5 times as long as broad, 3.1 times as long as pedicel; pedicel about 1.7 times as long as broad, 1.7 times as long as first funicle segment; first and second longer than broad; fourth and fifth distinctly broader than long; club 4-segmented, proximal three segments slightly transverse and apical segment conical-ovate. Otherwise like male.

Length : $0.6-0.7 \mathrm{~mm}$. 
Host: Cirphis unipuncta Haw., in China.

Distribution: Japan (Kyushu), Korea, China. This is the first record of this species from Japan and Korea.

Specimens examined: JAPAN: 3 males, 1 female, Kamiozoegawa, Fuji, Saga Pref., Kyushu, 10. viii. 1973 (K. Yamagishi) ; 3 males, Kamiozoegawa, Fuji, Saga Pref., Kyushu, 9. x. 1973 (K. Yamagishi) ;2 males, Kamiozoegawa, Fuji, Saga Pref., Kyushu, 5. vii. 1973 (K. Yamagishi) ; 1 male, Kamiozoegawa, Fuji, Saga Pref., Kyushu, 25. ix. 1973 (K. Yamagishi). KOREA: 1 male, 1 female, Mt. Sudo (700 m), Kyungsangpuk-do, Korea, 9-12. vii. 1971 (K. Yamagishi); 1 female, Pyungnae, Kyunggi-do, Korea, 1. ix. 1982 (J. Ryu).

\section{( 6) Telenomus lucullus Nixon}

(Fig. 23)

Telenomuslucullus Nixon, 1937, Ann. Mag. Nat. Hist., (10) 20: 451. Female.

The female of this species is similar to that of nakagawai, but easily separated from the latter in having the antennae and legs paler (predominantly yellowish). This is also very characteristic in having the preoccipital carina which is rather distinct even in the median portion.

Female: Black. Antennae honey yellow except for club of antennae which is dark brown. Legs pale yellow except for fore coxae and apical tarsal segments which are dark brown. Wings hyaline with pale yellowish veins.

Head transverse as seen from above, about 2.7 times as broad as its median length and slightly broader than thorax (21:16). Vertex convex, finely and evenly reticulate-sculptured with sparse, pale hairs; occiput markedly concave; preoccipital carina present, rather distinct even in the median portion. Frons well convex, broad, entirely smooth and shining; subocular space feebly punctate-rugose near eye. Eyes with very short hairs, 1.3 times as long as broad; interocular distance about 0.5 times as long as width of head as seen in front. Posterior ocelli very close to inner orbits; posterior ocellar distance about 1.8 times as long as lateral ocellar distance. Antennae 11-segmented with 4-segmented club; radicle rather long in proportion to scape (3:10), 3.1 times as long as broad; scape 5.4 times as long as broad, nearly equal to following five segments combined; pedicel as long as first funicle segment, about 1.7 times as long as broad; second a little longer than broad, nearly as long as second; fourth bead-like, as long as broad; fifth transverse; proximal three segments of club transverse and apical segment conical-ovate.

Thorax slightly longer than broad (11:9); mesoscutum convex, finely reticulate-sculptured throughout, covered with dense pale hairs; scutellum smooth and shining with a few sparse punctures, covered with pale hairs which are a little longer and sparser than those on mesoscutum; metanotum and propodeum strongly sculptured. Fore wings pale, about 2.6 times as long as broad; venation not sharply outstanding; stigmalis rather long, about 0.6 times as long as postmarginalis and submarginalis longer than postmarginalis (7:4). Hind wings about 5.3 times as long as broad; fringes a little longer than $1 / 2$ of the greatest width of hind wing.

Metasoma obviously longer than broad, about $11: 8$; first tergum trans. 
vers, costate at extreme base; second tergum slightly longer than broad (5 : 4), carinate at extreme base only; following terga extremely short.

Length : $0.9 \mathrm{~mm}$.

Male and host: Unknown.

Distribution : Japan (Kyushu), Java. This is the first record of this species from Japan.

Specimens examined: 1 female, Higashigusuku, Amami-Oshima, Kagoshima Pref., Kyushu, 13. xi, 1962 (Y. Miyatake) ; 1 female, Naze, Amami-Oshima, Kagoshima Pref., Kyushu, 7. xi. 1962 (Y. Miyatake).

\section{(7) Telenomus gifuensis Ashmead}

(Figs. 20, 26, 46)

Telenomus sp. Nakagawa, 1900, Spec. Rep. Agric. Exp. Stat., 6: 12.

Telenomus gifuensis Ashmead, 1904, J. New York Ent. Soc., 12: 73. Female.

Telenomus gifuensis: Brues, 1908, Gen. Insect., 80: 7.

Telenomus gifuensis: Kieffer, 1926, Das Tierreich, 48: 38. Female.

Teknomus gifuensis: Watanabe, 1951, Trans. Shikoku Ent. Soc., 2 (2): 17. Female and male.

Telenoms gifunesis: Hidaka, 1958, Acta Hym., 1: 75.

Teknomus gifuensis: Masner and Muesebeck, 1968, U. S. Nat. Mus. Bull., 270: 64.

This species is similar to lucullus, but differs from it in having the metasoma longer and head larger. This is further characterized by the vertex rather flat and broad, the postero-lateral portion just behind eye angulate, very narrow, coxae honey yellow and metasoma obviously longer than broad.

This species was originally described briefly by Ashmead (1904) from females taken from Japan (Gifu).

Female: Black. Antennae dark brown to black except for scape and apex of pedicel which are yellow or light yellowish brown. Legs including coxae yellow.

Head transverse as seen from above, about 2.7 times as broad as its median length and sligthly broader than thorax $(9: 8)$. Vertex rather flat, rather broad, finely reticulate-sculptured; occiput abruptly angled, but not keeled, with somewhat acute ridge or carina just behind eyes. Frons in front of mid ocellus well convex, smooth and shining; subocular space broadly, microscopically punctate-sculptured near eye. Eyes hairy, about 1.1 times as long as broad; interocular distance rather short, about 0.5 times as long as width of head as seen in front. Distance between eye and mandible short, as seen from side. Posterior ocellar distance 1.6 times as long as lateral ocellar distance. Antennae rather slender, 11-segmented; scape 5.8 times as long as broad, almost equal to pedicel and three funicle segments combined: pedicel 2.2 times as long as flrst funicle segment; second 1.3 times as long as broad, 0.6 times as long as first; third oblong, a little longer than broad; fourth rounded; club 5-segmented, proximal first segment rather small, three median segments quadrate and apical segment conically elongate.

Thorax a little broader than metasoma; mesoscutum distinctly convex, closely reticulate-sculptured, covered with very short, pale hairs; scutellum 
smooth, shining with sparse feeble punctures, covered with pale hairs which are a little longer and sparser than those on mesoscutum; postscutellum semicircular, strongly sculptured. Fore wings about 4 times as long as broad; postmarginalis 2.2 times as long as stigmalis, submarginalis 1.4 times as long as postmarginalis. Hind wings about 5.1 times as long as broad; fringes a little shorter than $1 / 2$ of the greatest width of hind wing.

Metasoma obviously longer than broad (9:6); first tergum strongly transverse, longitudinally costate; second tergum a little longer than broad, longitudinally striated at least on basal third medially, but these striae weak, short laterally ; elsewhere smooth and shining. Ovipositor slithtly projected.

Male: Antennae 12-segmented;scape 6.1 times as long as broad, slightly shorter than following four segments combined; pedicel 1.6 times as long as broad, 0.8 times as long as first flagellar segment; first to third clearly longer than fourth to ninth, about 1.9 times as long as broad; fourth to ninth a little longer than broad; apical segment conically pointed, 2.7 times as long as broad. Otherwise like female.

Length: Male $0.9 \mathrm{~mm}$, female 1. O-1. $1 \mathrm{~mm}$.

Host :Piezodorus rubrofasciatus Fabricius, Dolycoris baccarum L., Scotinophara lurida Burmeister, Eusarcoris ventralis Westwood, Piezodorus hybneri Gmelin, Scotinophara scotti Horváth, in Japan.

Distribution: Japan (Kyushu, Honshu, Shikoku), Korea, China. This is the first record of this species from Korea.

Specimens examined: JAPAN: 1 female, Kamiozoegawa, Fuji, Saga Pref., Kyushu, 13. iv. 1973 (K. Yamagishi) ; 1 female, Kamiozoegawa, Fuji, Saga Pref., Kyushu, 9. x. 1973 (K. Yamagishi) ; 1 female, Kamiozoegawa, Fuji, Saga Pref., Kyushu, 4. vii. 1973 (K. Yamagishi) ; 2 females, Kamiozoegawa, Fuji, Saga Pref., Kyushu, 21. ix. 1973 (K. Yamagishi) ; 1 male, 1 female, Kamiozoegawa, Fuji, Saga Pref., Kyushu, 10. vii. 1973 (K. Yamagishi) ; 1 female, Kamiozoegawa, Fuji, Saga Pref., Kyushu, 6. ix. 1973(K. Yamagishi) ; 2 males, Kamiozoegawa, Fuji, Saga Pref., Kyushu, 16. vi. 1973 (K. Yamagishi) ; 1 male, Matsuyama, Shikoku, 13. vii. 1950 (T. Ishihara), bred from eggs of Piezodorus rubrofas. ciatus Fab. KOREA : 1 female, Mt. Sudo (400 m), Kyungsangpuk-do, Korea, 1718. vii. 1971 (K. Yamagishi) ; 2 males, Mt. Sudo (1,000 m), Kyungsangpuk-do, Korea, 13-14. vii. 1971 (K. Yamagishi) ; 1 male, Mt. Sudo (700 m), Kyungsangpuk-do, Korea, 11-13. xi. 1971 (K. Tobi) ; 1 female, Mt. Chunmasan, Kyunggido, Korea, 6، ix. 1982 (J. Ryu).

\section{( 8 ) Telenomus nakagawai Watanabe}

(Figs. 22, 43)

Telenomus sp. Nakagawa, 1900, Spec. Rep. Agric. Exp. Stat., 6: 14. Female. Telenomus nakagawai Watanabe, 1954, Trans. Shikoku Ent. Soc., 4: 17. Female.

This species is very similar to gifuensis, but differs from the latter in having the antennae and coxae nearly black throughout, pedicel shorter than first funicle segment and the vertex not broad, not flat as in gifuensis, but narrow and convex.

Female: Black. Antennae dark brown to' black throughout but pedicel some- 
times paler and yellowish. Legs brownish except for femora slightly infuscated and coxae black. Wings hyaline, veins light yellowish brown. Ovipositor dark brown.

Head transverse as seen from above, about 2.3 times as broad as its median length and slightly broader than thorax (5:4). Vertex rather narrow, well convex and flnely reticulate-sculptured; occiput abruptly angled and with somewhat acute ridge or carina on the postero-lateral portions just behind eyes. Frons well convex, very broad, in greater part smooth and shining; subocular space microscopically punctate-sculptured near eye. Distance between eye and mandible rather long as seen from side. Eyes hairy, 1.4 times as long as broad; interocular distance 0.5 times as long as width of head; seen in front, inner eye margins distinctly diverging below except for upper portions which are also diverging laterally. Posterior ocellar distance 1.6 times as long as lateral ocellar distance. Antennae rather slender, IL-segmented; scape 5.2 times as long as broad, almost equal to pedicel and three funicle segments combined; pedicel twice as long as broad, shorter than first funicle segment; first 2.5 times as long as broad, 1.3 times as long as pedicel; second 1.7 times as long as broad, 0.7 times as long as first; third longer than broad; fourth as long as broad; fifth 1.2 times as long as fourth; club 4-segmented, not compact, each segment almost quadrate except for the apical segment which is pointed and 1.5 times as long as broad.

Thorax a little broader than metasoma; mesoscutum reticulate-sculptured all over, covered with pale hairs; scutellum nearly entirely smooth and shining, covered with also pale hairs; metanotum and propodeum strongly sculptured. Fore wings 2.5 times as long as broad; stigmalis rather long, postmarginalis about 1.7 times as long as stigmalis and submarginalis 1.5 times as long as postmarginalis. Hind wings 5 times as long as broad; fringes about $1 / 2$ of the greatest width of hind wing.

Metasoma clearly longer than broad (11:8); first tergum fransverse, strongly costate; second tergum about as long as broad, weakly longitudinally striated at base; third to seventh terga strongly transverse; ovipositor slightly projected.

Male: Antennae 12-segumented, rather slender and dark brown to black; scape 5.1 times as long as broad, 3.5 times as long as radicle; pedicel slightly longer than broad, shorter than first flagellar segment; first about twice as long as broad, 1.9 times as long as pedicel; second about as long and broad as first; third 1.7 times as long as broad, 0.9 times as long as second ; fourth to ninth slightly longer than broad; apical segment 2.7 times as long as broad. Otherwise like female, but head and metasoma smaller.

Length: Male $0.9 \mathrm{~mm}$, female $1.2 \mathrm{~mm}$.

Host: Nezara antennata Scott.

Distribution: Japan (Kyushu, Honshu, Shikoku).

Specimens examined: 1 female, Kamiozoegawa, Fuji, Saga Pref., Kyushu, 19. v. 1973 (K. Yamagishi) ; 1 male, Kamiozoegawa, Fuji, Saga Pref., Kyushu, 4. vii. 1973 (K. Yamagishi). 


\section{(9) Telenomus benefactor Crawford}

(Figs. 10, 33)

Telenomus benefactor Crawford, 1911, Proc. U. S. Nat. Mus., 40: 439. Female and male. Microphanurus benefactor: Kieffer, 1926, Das Tierreich, 48: 103. Female and male.

Telenomus benefactor: Nixon, 1935, Trans. R. Ent. Soc., Lond., 83 (1) : 87. Female and male.

This species is similar to strelzovi, but differs from the latter in having the metasoma distinctly longer than head and thorax combined, the first metasomal tergum virtually unsculptured and ovipositor very long.

Female: Antennae dark brown to black. Legs brownish with femora infuscated.

Head not strongly transverse as seen from above, about 1.9 times as broad as its median length and slightly broader than thorax; head with posterolateral portions just behind eyes rounded, usually well developed. Vertex broad, not sharply angled, roundly convex into occiput, very feebly but closely reticulate-sculptured with very short hairs ; occiput concave and preoccipital carina situated below the top of vertex. Frons above antenna1 toruli with a feeble ill-defined impression, entirely smooth and shining but microscopically sculptured along the inner orbit. Eyes rather large, pilose and about 1.4 times as long as broad; interocular distance about 0.4 times as long as width of head. Interocellar space triangular and posterior ocellar distance about 1.6 times as long as lateral ocellar distance. Antennae 11-segmented with 4-segmented club; scape 5.2 times as long as broad, a little longer than pedicel and three funicle segments combined; pedicel 1.5 fimes as long as first funicle segment; first about 1.7 times as long as broad, slightly longer than second; second and third slightly longer than broad; fourth bead-like and fifth transverse; proximal three segments of club transverse and apical segment conical-ovate.

Thorax longer than broad (11:8); mesoscutum somewhat dull, with some feeble and indefinite sculpture like vertex, covered with short hairs; scutellum smooth and shining, with a few scattered punctures; postscutellum not glabrous with distinct sculptures. Fore wings rather long, about 3.1 times as long as broad and venation not sharply defined; postmarginalis indistinct, bi certainly more than twice as long as stigmalis; submarginalis longer than postmarginalis, about $11: 8$. Hind wings narrow, about 5.9 times as long as broad; fringes a little longer than $1 / 2$ of the greatest width of hind wing.

Metasoma distinctly longer than head and thorax combined (11:9) ; first tergum virtually unsculptured, smooth and shining except for extreme base; second tergum longer than broad $(11: 8)$, striated at base; third to seventh terga distinctly transverse with sparse, rather long hairs; ovipositor about 0.6 times as long as metasoma.

Length: $1.2-1.5 \mathrm{~mm}$.

Host: Tabanus taeniola P. de Beauvoir, in Sudan; Tabanus biguttatus, in Nyasaland.

Distribution: Japan (Kyushu), Korea, Sudan, Nyasaland. This is the first record of this species from Japan and Korea. 
Specimens examined: JAPAN: 1 female, Kamiozoegawa, Fuji, Saga Pref., 19. v. 1973 (K. Yamagishi) ; 1 female, Kamiozoegawa, Fuji, Saga Pref., Kyushu, 5. vi. 1973 (K. Yamagishi) ; 1 femae, Kamiozoegawa, Fuji, Saga Pref., Kyushu, 13. iv. 1973 (K. Yamagishi). KOREA: 1 female, Mt. Sudo (700 m), Kyungsangpuk-do, Korea, l-4. vi. 1971 (S. Suzuki) ; 1 female, Mt. Sudo (400 m), Kyungsangpuk-do, Korea, 17-18. vii. 1971 (K. Yamagishi) ; 2 females, Mt. Baikbong. san, Kyunggi-do, Korea, 22. vii. 1982 (J. Ryu) ; 1 female, Mt. Baikbongsan, Kyunggi-do, Korea, 5. viii. 1982 (J. Ryu).

(10) Telenomus wullschlegeli Mayr

(Figs. 11, 32, 50)

Telenomus wullschlegeli Mayr, 1879, Verh. zool. bot. Ges., Wien, 29: 701, 711. Female.

Prophanurus wullschlegeli: Kieffer, in André, 1912, Spec. Hym. Eur., 11: 54. Female and male.

Telenomus wullschlegeli: Kieffer, 1926, Das Tierreich, 48: 35. Female and male.

Telenomus wullschlegeli:Lozlov, 1967, Ent. Obozr., 46: 363. Female and male.

This species is similar to benefactor, but differs from the latter in having the head not thick, and transverse, as seen from above, frons hardly convex, rather broadly flat and metasoma distinctly concave.

Female: Black. Antennae dark brown. Legs predominantly dark brown except for apex of tibiae and tarsi yellowish brown. Wings tinged with pale brownish, veins brown. Ovipositor dark brown.

Head extremely transverse as seen from above, 3.4 times as broad as its median length and slightly broader than thorax (11 : 10). Vertex rather flat, reticulate-sculptured with sparse, pale hairs ; occiput concave, not sharply margined. Frons hardly convex, rather broadly flat with scatterred punctures and sparse, very short hairs. Eyes distinctly narrow with short hairs, 1.5 times as long as broad; interocular distance about 0.5 times as long as width of head. Posterior ocelli very close to inner orbit; posterior ocellar distance about 1.8 times as long as lateral ocellar distance. Antennae 11-segmented; scape rather short, 4.2 times as long as broad and 2.4 times as long as pedicel; pedicel about 2.1 times as long as broad, 1.4 times as long as first funicle segment; first 1.7 times as long as broad, a little longer than second; second and third a little longer than broad; fourth bead-like; fifth a little transverse; club 4-segmented, proximal first segment quadrate, second and third slightly transverse and apical segment conical ovate.

Thorax dorso-ventrally distinctly compressed, 1.3 times as long as broad; mesoscutum distinctly flat with fine reticulate sculptures, which tend to become sparse and smooth posteriorly with sparse, very short hairs; scutellum semicircular, distinctly smooth and shining; postscutellum very short, smooth and not swelling; propodeum rather broad with tine punctures. Fore wings about 3.1 times as long as broad; stigmalis about 1/2 as long as postmarginalis which is indistinct, but slightly shorter than submarginalis. Hind wings rather slender, about 6.1 times as long as broad; fringes about $2 / 3$ of the greatest width of hind wing. 
Metasoma distinctly concave, hardly longer than twice as long as broad; first tergum transverse, longitudinally costate at base; second tergum just longer than broad with extremely short striae at base; following terga very short with sparse hairs; ovipositor slightly projected, about 1/3 of metasoma.

Male: Differs from female as follows: Antennae dark brown, with scape and pedicel yellowish brown. Legs more paler than those of female. Metasoma not sharply pointed apically and shorter than that of female. Antennae 12-segmented; scape 3.7 times as long as broad, 2.9 times as long as pedicel; pedicel a little shorter than first flagellar segment; first and third nearly equal in length; second 2.2 times as long as broad, slightly longer than other segments; fourth to ninth almost equal in length; apical segment conicalovate, 1.9 times as long as broad.

Length: Male $0.95 \mathrm{~mm}$, female $1.0 \mathrm{~mm}$.

Host: Bombyx lanestris, Bombyx castrensis Mayr, in Austria ; Eurygaster lanestris L., in USSR.

Distribution: Japan (Kyushu), Austria, USSR (Moldavia). This is the first record of this species from Japan.

Specimens examined: 1 female, Kamiozoegawa, Fuji, Saga Pref., Kyushu, 4. vii. 1973 (K. Yamagishi) ; 1 male, Kamiozoegawa, Fuji, Saga Pref., Kyushu, 10. viii. 1973 (K. Yamagishi).

\section{(11) Tetenomus sphaeroceps Ryu, sp. n.}

(Figs. 12, 13, 35, 56)

This species is recognizable from other species by the size very small (length about $0.6 \mathrm{~mm}$ ), head rounded and distinctly convex in front with distinctly concentrated and well developed granulae on posterior portions of head behind eyes, face situated on ventral part of head, scutellum not sharply defined, antennae slender and the fringes of hind wing almost equal to the greatest width of wing.

Female: Black. Antennae dark brown. Legs fuscous except for trochanters and tarsi which are yellowish brown. Wings hyaline, veins pale yellow. Ovipositor yellowish brown.

Head about 1.3 times as broad as its median length and a little broader than thorax (15:14), as seen from above; posterior portions behind eyes very well developed. Vertex and occiput slightly rounded from mid ocellus to occiput with extremely weak granulae. Face situated on ventral part of head because frons strongly produced anteriorly, with a remarkably concentrated granulae. Frons almost smooth and shining; subocular space with a few punctures near eye. Eyes sparsely hairy, not attanining to posterior margins of head, temple as broad as eye as seen from side ; eye about 1.5 times as long as broad. Posterior ocelli very close to inner orbit. Antennae rather slender, 11-segmented; scape 4 times as long as broad, almost equal to following three segments combined ; pedicel about 2.4 times as long as broad, 1.9 times as long as first funicle segment which is a little longer than other funicles; first to fourth a little longer than broad; fifth as long as broad; club 4-seg. 
mented, proximal first and second as long as broad, third transverse and apical segment subconical.

Thorax longer than broad (19:14), nearly as broad as metasoma; mesoscutum rather flat, reticulate-sculptured throughout; outlines of scutellum and postscutellum indistinct, scutellum glabrous with sparse punctures. Fore wings about 3.1 times as long as broad; stigmalis about 1/2 as long as postmarginalis and submarginalis about twice as long as postmarginalis. Hind wings rather slender, about 8.4 times as long as broad; firinges almost equal to the greatest width of hind wing.

Metasoma elongate, about 2.1 times as long as broad; first tergum transverse, costate on its extreme base; second tergum a little longer than broad, basal striae very short; following terga transverse and acuminated apically. Ovipositor projecting, about quarter as long as metasoma.

Length : $0.6 \mathrm{~mm}$.

Male and host: Unknown.

Distribution : Japan (Kyushu).

Type material: Holotype : female (Type No. 2216, Kyushu Univ.), Kamiozoegawa, Fuji, Saga Pref., Kyushu, 9. x. 1973 (K. Yamagishi). Paratype: 1 female, Kamiozoegawa, Fuji, Saga Pref., Kyushu, 6. ix. 1973 (K. Yamagishi).

\section{(12) Tetenomus yamagishii Ryu, sp. n.}

(Figs. 14, 36, 51, 57)

General form nearly as in strelzovi, but the vertex roundly slanting into occiput, club of antennae clearly 4-segmented, brown, distinctly contrasting to the rest of antennae which are yellow, legs also yellow, the metasoma rather broad and second tergum longitudinally weakly striated nearly all over.

Female: Black. Legs entirely deep yellow. Antennae deep yellow except for the club dark brown.

Head not strongly transverse as seen from above, about 1.8 times as broad as its median length and a little broader than thorax. Vertex distinctly broad, roundly convex, slanting posteriorly with fine reticulate-sculptures and sparse, pale hairs; postero-lateral portions just behind eyes broadly, roundly well developed with fine reticulation. Frons, in a dorsal view of the head, more evenly and noticeably flattened than in strelzovi, and its surface finely reticulate-sculptured throughout. Eyes with sparse, short hairs visible at $\mathrm{x} 100$, not attaining to posterior margins of head above ; eye 1.2 times as long as broad; interocular distance to width of head, as 7: 15, as seen in front. Posterior ocellar distance about 1.6 times as long as lateral ocellar distance. Antennae 11-segmented; scape 4 times as long as broad, almost equal to following four segments combined; pedicel about 1.8 times as long as broad, 1.4 times as long as first funicle segment; first slightly longer than broad (8: 6.5), 1.2 times as long as second; second as long as broad, hardly longer than third; third as long as broad; fourth and fifth transverse ; club 4-segmented, very thick and compact, proximal three segments transverse and apical segment conical-ovate. 
Thorax slightly longer than broad ( $8: 7)$; mesoscutum slightly flattened above, finely reticulate-sculptured as in vertex and covered with very short hairs; scutellum rather large, microscopically sculptured with sparse, short hairs; postscutellum transverse, distinctly sculptured. Fore wings about 2.7 times as long as broad; stigmalis 0.5 times as long as postmarginalis and submarginalis about 1.5 times as long as postmarginalis. Hind wings 6.1 times as long as broad; fringes about $1 / 2$ of the greatest width of hind wing.

Metasoma slightly longer than thorax $(5: 4)$, rather broad, about 1.4 times as long as broad; first tergum transverse, strongly costate nearly to apex; second tergum as long as broad, longitudinally weakly striated on basal $3 / 4$; third to seventh terga strongly transverse, smooth and impunctate with sparse hairs. Ovipositor projected about $1 / 3$ of metasoma.

Male: Antennae and legs brownish; scape more paler than other segments and apical segments of tarsi brownish black.

Antennae 12-segmented, each segment longer than broad; radicle 3 times as long as broad; scape about 3.7 times as long as broad, 3.1 times as long as pedicel; pedicel 1.5 times as long as broad, shorter than following segments ; first flagellar segment about 1.7 times as long as broad, 1.2 times as long as second; second 1.8 times as long as broad, a little longer than third ; third 1.5 times as long as broad, hardly longer than fourth; fourth as long as fifth, a little shorter than sixth; sixth and seventh subequal and subquadrate, a little longer than eighth; eighth about 1.4 times as long as broad, 0.9 times as long as ninth; ninth 1.3 times as long as broad; apical segment conically elongate, about twice as long as broad. Otherwise like female.

Length : 0.8-O. $85 \mathrm{~mm}$.

Host: Unknown.

Distribution : Japan (Kyushu).

Type material: Holotype: female (Type No. 2217, Kyushu Univ.), Kamiozoegawa, Fuji, Saga Pref., Kyushu, 6. ix. 1973 (K. Yamagishi). Paratypes: 1male, 3 females, Kamiozoegawa, Fuji, Saga Pref., Kyushu, 6. ix. 1973 (K. Yamagi. shi).

\section{(13) Telenomus poeta Girault}

Telenomus poeta Girault, 1920, Proc. U. S. Nat. Mus., 58: 178. Female.

Telenomus poeta: Masner and Muesebeck, 1968, U. S. Nat. Mus. Bull., 270: 69.

Telenomus poeta: Hirashima and Yamagishi, 1981, J.Fac. Agr., Kyushu Univ., 25 (4) :158159.

This is a rather large, more or less robust species which is easily known by the head being transverse and rounded in outline as seen from above.

This species was originally described by Girault (1920) from central Japan from three females bred from the eggs of Dictyoploca japonica (Moore). One of them was designated as the lectotype by Masner and Muesebeck in 1968. Type No. 20604, USNM.

For the redescription of this species, see Hirashima and Yamagishi (1981).

Length: About $1.2 \mathrm{~mm}$.

Male: Unknown. 
Host : Dictyoploca japonica (Moore).

Distribution: Japan (central Japan, Kyushu).

Specimen examined: 1 female, Kamiozoegawa, Fuji, Saga Pref., Kyushu, 25. ix. 1973 (K. Yamagishi).

\section{(14) Telenomus strelzovi Vassiliev}

(Figs. 15, 29, 48)

Telenomus strelzovi Vassiliev, 1949, Trudȳ vses. inst. zashch. rast., 2: 109-110. Female.

Telenomus strelzovi: Kozlov, 1967, Ent. Obozr., 46: 369. Female and male.

This species is similar to benefactor, but differs from the latter in having the head not so transverse and body slender and smaller. This is readily recognizable by the head with postero-lateral portions just behind eyes rounded, well developed, interocular distance rather short, vertex fairly, roundly convex into occiput, preoccipital carina situated below the top of vertex, antennae rather slender and metasoma elongate, lanceolate.

Female: Black. Antennae dark brown with scape and pedicel yellowish brown. Legs predominantly dark brown except for apex of femora, tibia and basal three segments of tarsi which are digny yellow. Wings hyaline, veins brown. Ovipositor dark brown.

Head for the genus less transverse than usual as seen from above, 1.6 times as broad as its median length and a little broader than thorax (11:9); head, as seen from above, with postero-lateral portions just behind eyes rounded, well developed. Vertex remarkably roundly convex into occiput with fine reticulate sculpture throughout; occiput concave and preoccipital carina situated below the top of vertex. Frons almost smooth and shining; subocular space feebly punctate-rugose near eye; marginal keels somewhat grooved. Eyes with extremely short hairs, 1.2 times as long as broad; its width almost equal to that of temple as seen from side; interocular distance about 0.5 times as long as width of head as seen in front. Posterior ocelli very close to inner orbit; posterior ocellar distance 1.4 time as long as lateral ocellar distance. Antennae ll-segmented with 4-segmented club; scape 5 times as long as broad, 3.7 times as long as radicle; pedicel 2.2 times as long as broad, 1.6 times as long as first funicle segment; first 1.4 times as long as broad, nearly as long as second; third 1.4 times as long as broad, a little shorter than second; fourth as long as broad, 0.8 times as long as third; fifth a little transverse, 0.9 times as long as broad; proximal first segment of club a little transverse, 0.7 times as long as second and apical segment conical-ovate.

Thorax distinctly longer than broad (11:7), a little broader than metasoma; mesoscutum rather flat, finely reticulate-sculptured throughout, covered with short hairs; scutellum smooth and shining, covered with also sparse, short hairs; metanotum and propodeum distinctly sculptured. Fore wings about 3 times as long as broad; stigmalis about $1 / 2$ as long as postmarginalis and submarginalis 1.5 times as long as postmarginalis. Hind wings 7 times as long as broad; fringes about $4 / 5$ of the greatest width of hind wing.

Metasoma rather long and lanceolate ; 2.3 times as long as broad and al- 
most equal to head and thorax combined; first tergum virtually unsculptured except for the extreme base; second tergum slightly longer than broad $(9: 7)$, longitudinally striated on basal quarter; third to seventh terga very short and tapering with sparse, pale hairs; ovipositor projecting about $1 / 3$ of metasoma.

Male: Antennae 12-segmented; scape rather short, 2.8 times as long as radicle, 3.4 times as long as broad; pedicel 1.4 times as long as broad, 0.8 times as long as first flagellar segment; first 1.9 times as long as broad, 0.8 times as long as second; second 2.5 times as long as broad, a little longer than third; third twice as long as broad, 1.5 times as long as fourth; fourth to ninth cylindrical and shorter than other segments; apical segment conical, 2.5 times as long as broad. Otherwise like female.

Length: $0.95 \mathrm{~mm}$.

Host: Adelphocoris lineolatus Gz. (in USSR).

Distribution: USSR (Moldavia), Korea. This is the first record of this species from Korea.

Specimens examined: 2 females, Mt. Sudo (400 m), Kyungsangpuk-do, Korea, 17-18. vii. 1971 (K. Yamagishi) ; 1 male, 1 female, Mt. Sudo (1,000 m), Kyungsangpuk-do, Korea, 13-14. vii. 1971 (K. Yamagishi) ; 2 females, Mt. Baikbongsan, Kyunggi-do, Korea, 22. vii. 1982 (J. Ryu) ; 1 female, Kwangneung, Kyunggi-do, Korea, 9. ix. 1982 (J. Ryu) ; 4 females, KAERI., Seuol, Korea, 5. vii. 1982 (J. Ryu).

\section{(15) Telenomus sp.}

(Figs. 16, 34, 55)

This species is very similar to dignus in the shape of head and metasoma, but differs from the latter in having the vertex broad with extremely short hairs, occiput distinctly concave, eyes rather large, interocular distance very short and the head not so transverse.

This is apparently a new species. Very unfortunately, however, this is known by a single specimen to us. Therefore no specific name is given in this paper.

Female: Black. Antennae chestnut brown except for radicle, scape and apex of pedicel which are yellowish brown. Legs honey yellow except for the fore coxae brown. Wings hyaline, veins yellowish brown and ovipositor honey yellow.

Head not strongly transverse as seen from above, about twice as broad as its median length, approaching a subcubical in form and slightly broader than thorax (11: 9). Vertex rather broad and evenly rounded; postero-lateral portions behind eyes well developed; preoccipital margin concave, rather deeply excavated, not close to the top of vertex and situated below the top of vertex; its surface faintly reticulate-sculptured throughout. Frons smooth, shining and punctate-sculptured along the inner orbit; subocular space finely punctate-sculptured near eye. Eyes rather large with sparse, short hairs, about 1.4 times as long as broad; interocular distance to width of head, as 

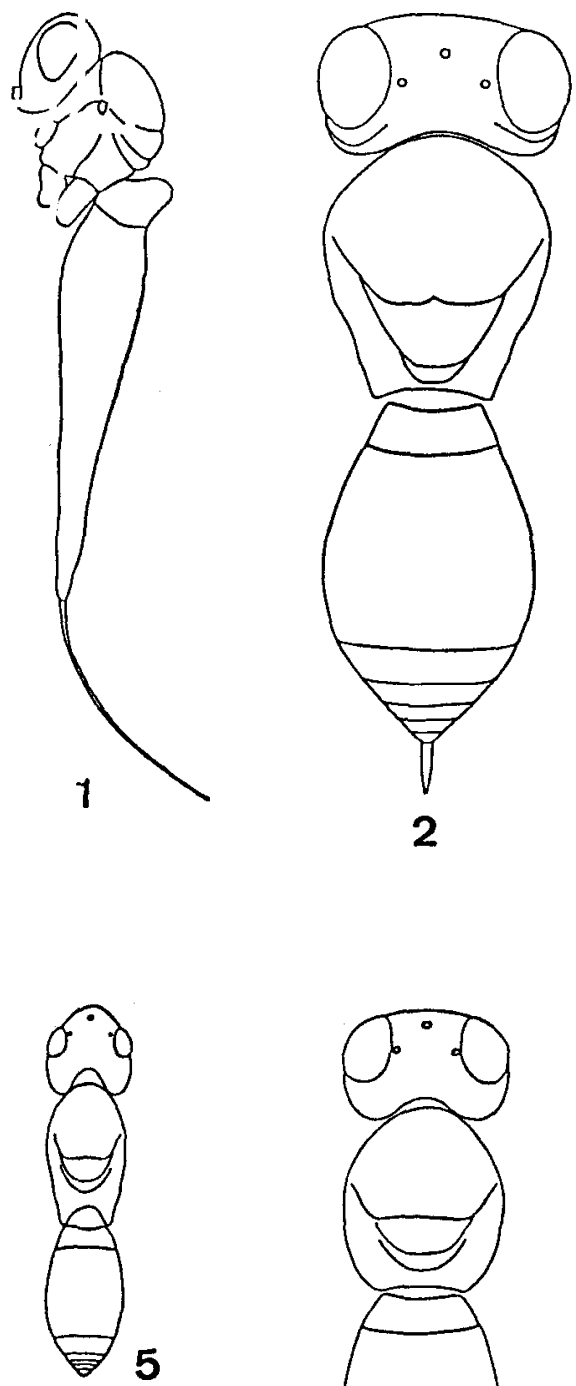

6
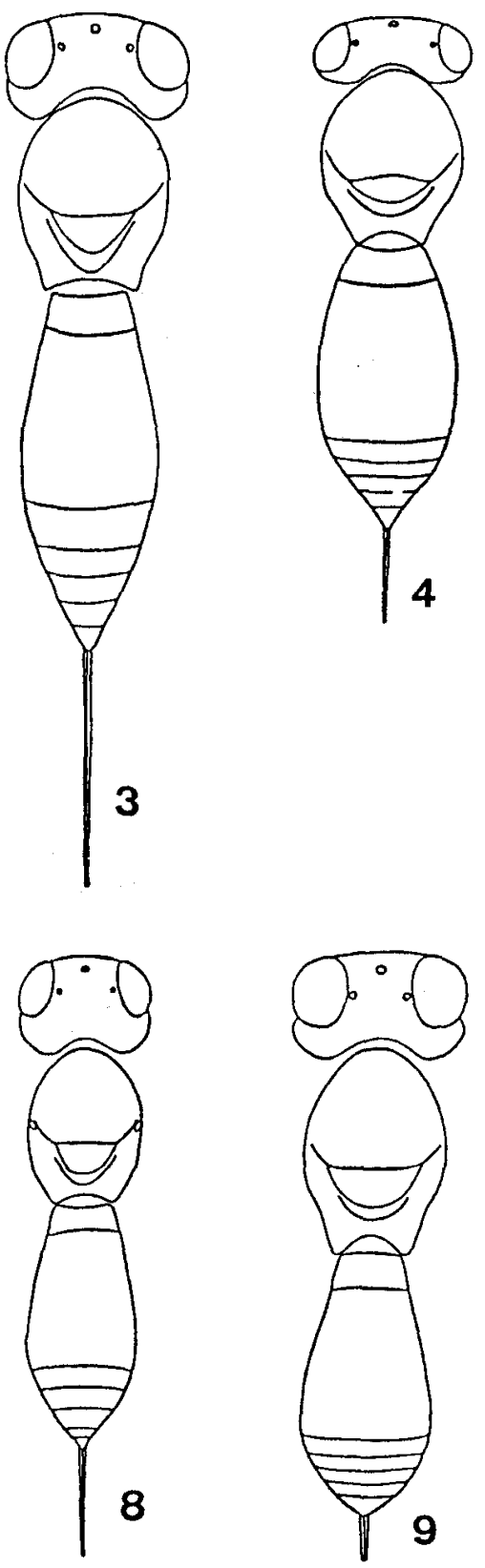

Figs. 1-9: Body and head of Telenomus spp., female. 1: T. promachivorus (Gahan), lateral view, 2: T. koreanus Ryu, sp. n., dorsal view. 3: T. benefactor Crawford, dorsal view, 4: T. wullschlegeli Mayer, dorsal view, 5: T. sphaeroceps Ryu, sp. n., dorsal view, 6: T. sphaeroceps Ryu, sp. n., lateral view, 7: T. yamagishii Ryu, sp. n., dorsal view, 8: T. strelzovi Vassiliev, dorsal view, 9: $T$. sp.. dorsal view. 


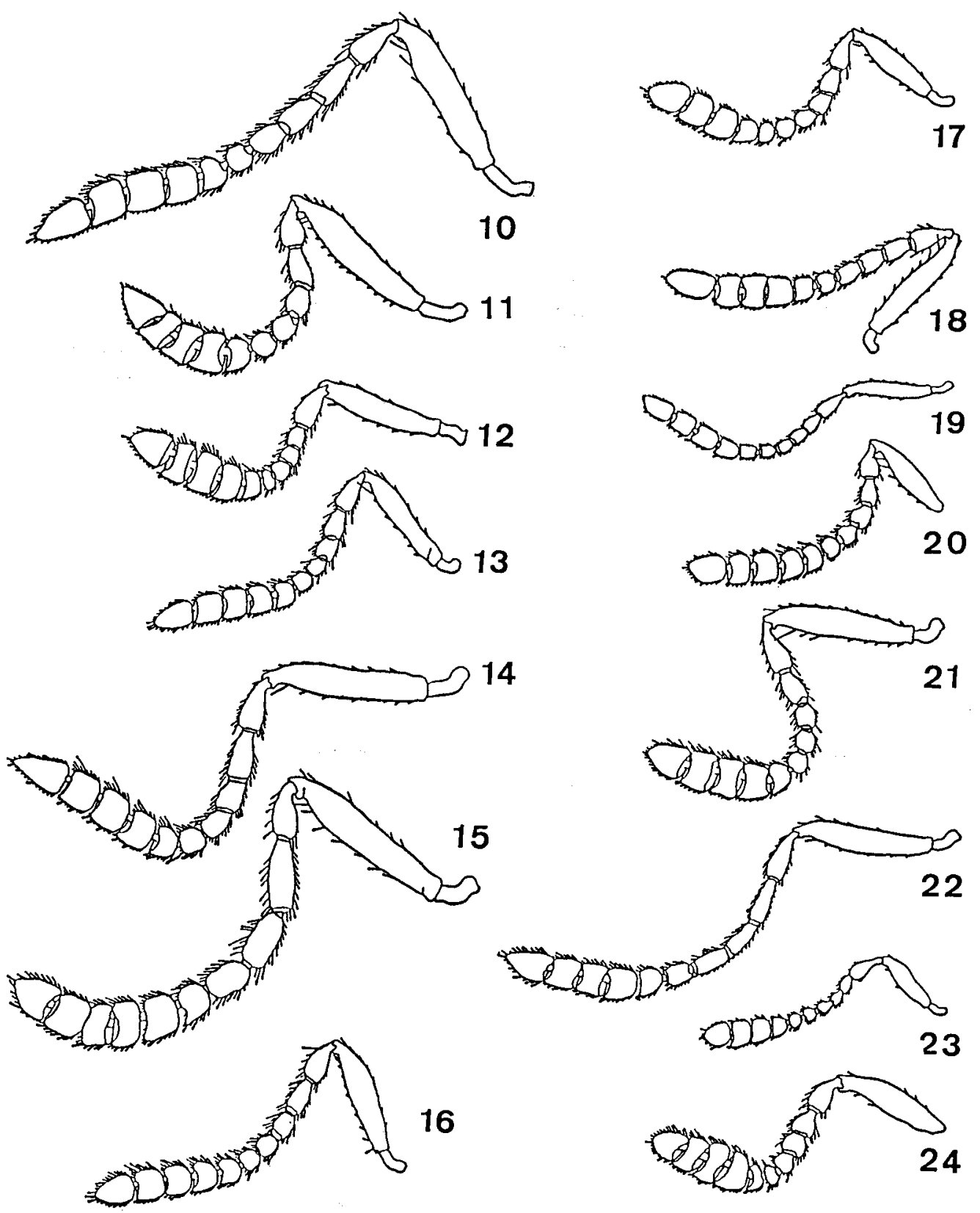

Figs. 10-24: Female antennae of Telenomus spp. 10: T. nakagawai Watanabe, 11: T. lucullus Nixon, 12: T. cirphivorus Liu, 13 : T. acrobates Giard, 14: T. gifuensis Ashmead, 15: T. koreanus Ryu, sp. n., 16: T. promachivorus (Gahan), $17: \mathbf{T}$. strelzovi Vassiliev, 18: T. dignus (Gahan), 19: T. rowani (Gahan), 20: T. wullschlegeli Mayr, 21: T. benefactor Crawford, 22: T. sp., 23: T. sphaeroceps Ryu, sp. n., 24: T. yamagishii Ryu, sp. n. 

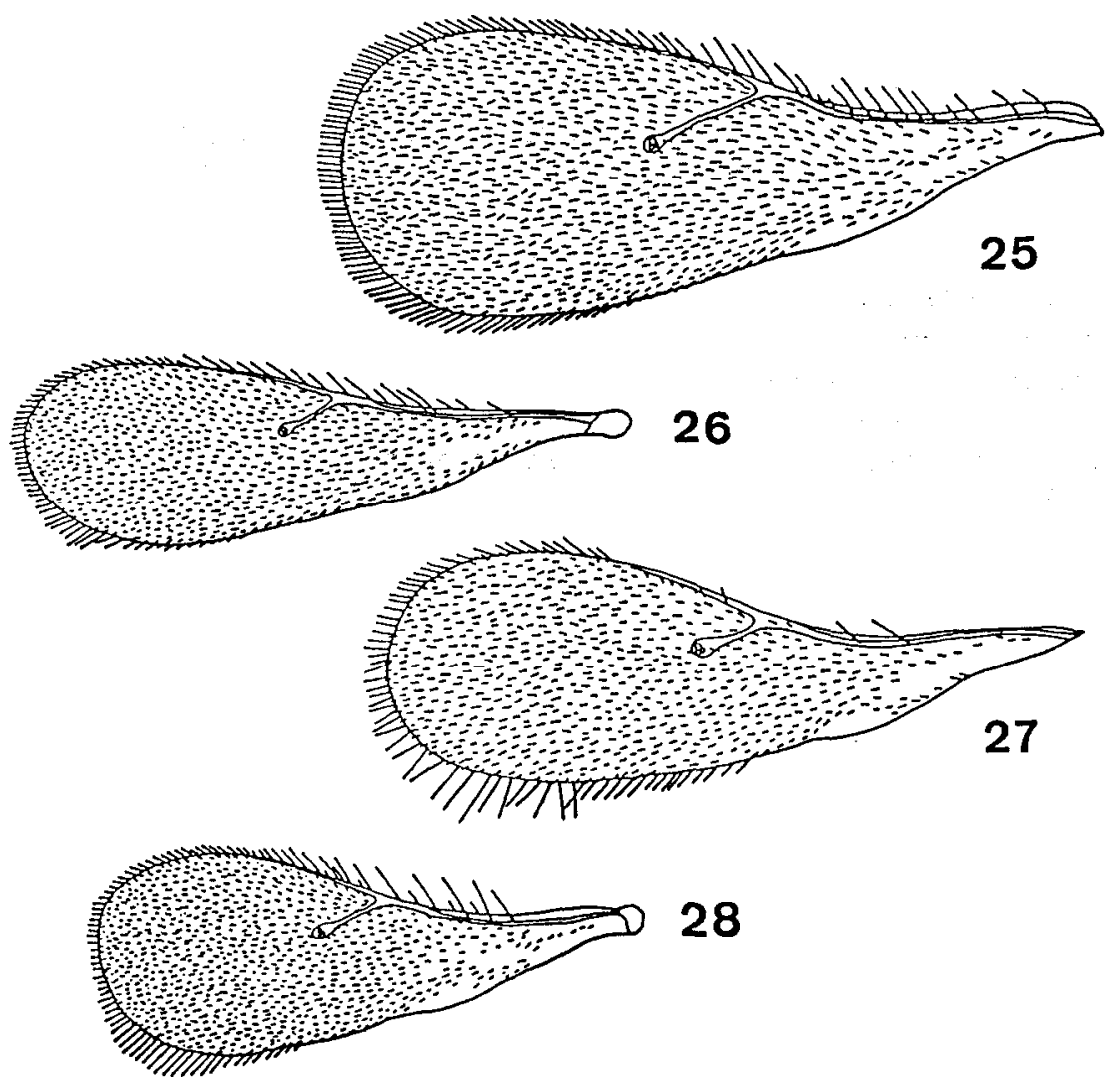

Figs. 25-28: Female fore wings of Telenomus spp. 25: T. koreanus Ryu, sp. n., 26: T. sp., 27: T. sphaeroceps Ryu, sp. n., 28: T. yamagishii Ryu, sp. n.

$3: 8$, as seen in front. Posterior ocellar distance about 1.4 times as long as lateral ocellar distance. Antennae rather long, 11-segmented; radicle about 2.6 times as long as broad, about $1 / 4$ as long as scape ; scape 5.3 times as long as broad, a little shorter than pedicel and two funicle segments combined; pedicel about 2.7 times as long as broad, barely longer than first funicle segment ; first 3 times as long as broad, 1.3 times as Iong as second ; second 2.3 times as long as broad, about 1.1 times as long as third ; third 1.9 times as long as broad, about 1.4 times as long as fourth which is longer than broad; club I-segmented, proximal three segments transverse and apical segment conical ovate.

Thorax rather elongate, about 1.5 times as long as broad and a little broader than metasoma ; mesoscutum rather convex, feebly reticulate-sculptured, ocvered with dense short yellowish hairs; scutellum rather convex, smooth and shining with scattered punctures. Fore wings elongate, about 3.4 times as long as broad; stigmalis about 0.4 times as long as postmarginalis 
and submarginalis about 1.6 times as long as postmarginalis. Hind wings rather narrow, about 6.6 times as long as broad; fringes only a little longer than $1 / 2$ of the greatest width of hind wing.

Metasoma a little more than twice as long as broad; first tergum with well-marked longitudinal costae on basal half; second tergum slightly longer than broad (5:4) with distinct striae on basal third; following terga extremely short with sparse, rather long hairs; ovipositor projecting a little beyond the tip of metasoma.

\section{Length: $1.0 \mathrm{~mm}$.}

Male and host: Unknown.

Distribution: Japan (Kyushu).

Specimens examined: 1 female, Kamiozoegawa, Fuji, Saga Pref., Kyushu, 4. vii. 1973 (K. Yamagishi). 